\title{
NUEVAS APORTACIONES AL CATÁLOGO DE LA OBRA DE LOS PINTORES JUAN DE ROELAS Y JUAN DEL CASTILLO
}

\author{
POR \\ ENRIQUE VALDIVIESO \\ JOSÉ FERNÁNDEZ LÓPEZ \\ Universidad de Sevilla
}

\begin{abstract}
The aim of this paper is to present 13 new canvas proceeding from artist belonging to the sevillian school Juan de Roelas and Juan del Castillo. This contribution allows to increase the catalogue of the work of these old masters of exceptional importance in sevillian painting from the first middle of the century xvir.
\end{abstract}

La biografía y el estudio de la obra de los pintores sevillanos del primer tercio del siglo XVII, Juan de Roelas y Juan del Castillo, fueron trazados y analizados ampliamente en los trabajos de Valdivieso, en 1978, y de Valdivieso y Serrera conjuntamente, en $1985^{~}$ '. Posteriormente diversos estudiosos generales sobre la pintura española sólo han insistido, con algunas aportaciones, en las características ya apuntadas por los citados investigadores. Lógicamente en el transcurso de estos años, desde la aparición de aquellos trabajos, se han producido hallazgos y aportaciones al catálogo de la obra de estos pintores. He ahí el objeto de este estudio, presentar y comentar estas nuevas obras y, además, reflexionar desde la experiencia sobre el estilo de ambos artistas.

Comenzamos por el clérigo pintor Juan de Roelas (h. 1560-1625), uno de los pintores de mayor edad de su generación y el acicate más importante para la renovación naturalista en la pintura sevillana de comienzos del barroco. Este pintor realizó o completó su formación artística en Italia, hacia 1585-1595, posiblemente en un ambiente cercano al estilo veneciano, aunque sin excluir otras posibles influencias ${ }^{2}$, lo que repercutió en su dibujo y en el empleo de tonalidades cálidas y suntuosas y de atmósferas de brillantes matices. En sus pinturas intervienen personajes con vida y sentimientos varios expresados con naturalidad cercana a la vida real.

I Valdivieso, E., Juan de Roelas, Sevilla, 1978; Valdivieso, E. y Serrera, J.M., Pintura sevillana del primer tercio del siglo xvII, C.S.I.C., Madrid, 1985, pp. 117 - 173 y $303-369$, láms. 88 - 140 y 210 - 262. Respecto a Roelas fue pionero el trabajo de Diego Angulo, «Juan de Roelas. Aportaciones para un estudio», en Archivo Español de Arte y Arqueología, vol. I, 1925, p. 103.

2 Valdivieso, E., Ob. cit., 1978, p. 28; Previtali, G., La pittura del cinquecento a Napoli e nel vicereame, Turín, 1978, pp. $110-115$. 
Sus obras principales de gran formato evidencian este estilo, como el gran lienzo de La Circuncisión del retablo de la iglesia de la Anuciación en Sevilla, hacia 1605, el Tránsito de San Isidoro de la parroquia de este santo en Sevilla, documentada en 1613, o El martirio de San Andrés, hoy día en el Museo de Bellas Artes de Sevilla, realizado entre 1610 y 1615; también presente en sus obras de pequeño formato. El naturalismo que caracterizó el quehacer de este pintor pudo hacer que fuera el introductor en la escuela sevillana de un tema religioso, profundamente humano, sencillo y entrañable, la Virgen con el Niño, también llamado Virgen de Belén. Este asunto, tradicional en las escuelas italianas, no figuraba en la nómina de obras conservadas en la pintura sevillana de aquel momento, aunque sí en la española. Bien es cierto que, con otros personajes, en diferentes iconografías, las figuras de María portando en su regazo al Niño Jesús fue habitual, pero no independientes y siempre acompañadas al menos de ángeles. Por ello la pintura de Roelas que presentamos posee un doble valor. En primer lugar, esta Virgen con el Niño (fig. n. ${ }^{\circ}$ 1), guardada en la colección del Patrimonio Nacional en los Reales Alcázares de Sevilla, es una obra de excelente calidad en la producción de este pintor, datable hacia $1610-1615^{3}$. Por otra parte puede ser, hasta el momento, la primera pintura con esta iconografía en la escuela sevillana.

La composición presenta un esquema típico triangular o piramidal, con la imagen de la Virgen sentada, atendiendo solícita y amorosamente al Niño, vistiendo túnica rósea, manto azul oscuro y un velo transparente que cubre parte de la cabeza. El nimbar blanco luminoso configura la disposición del celaje posterior con cabezas de ángeles sobre fondo azul añil intenso. El Niño Jesús, casi desnudo, está representado con dinamismo y agilidad expresiva, portando una pequeña cruz de madera en la mano izquierda, mientras bendice con la derecha. Debe destacarse la gran calidad de la pieza, que encaja en el estilo y en los modelos en la época antes citada, la que recoge las mejores piezas de la producción de Roelas.

En la República Checa y en el palacio de Mnichovo Hradiste se conserva una monumental representación pictórica de la Conversión de San Pablo ${ }^{4}$, obra que puede atribuirse a Juan de Roelas con cierta seguridad dado que las características de su estilo concuerdan plenamente con las de este pintor en los años que oscilan en torno a $1620^{5}$. La composición de esta obra, resuelta en formato vertical, está centrada por la figura de Pablo que, derribado de su caballo por una fuerza divina, recibe desde el cielo el mensaje de Cristo que le interpela por su persecución a los cristianos. La figura de Pablo, que se incorpora del súelo merced a la ayuda que le presta su escolta, marca una aparatosa expresividad que se refuerza con el movimiento de sus brazos abiertos y la tensión dramática que se refleja en su rostro, con los ojos vueltos hacia lo alto. Dicha expresividad se extiende al resto de la parte inferior de la escena promovida por los impetuosos y rudos gestos de los personajes de su séquito y del caballo que figura en un lateral de la escena (fig. $n .^{\circ} 2$ ).

El sentido de la fragilidad de lo humano que el artista ha sabido otorgar a la parte inferior de la composición contrasta con la serena grandiosidad divina a través de la figura de Cristo que en zona superior, y en medio de un áureo rompimiento de gloria, envía su mensaje al futuro apóstol.

En la Historia del Arte es frecuente encontrar a todos los niveles personajes conocidos, fundamentalmente, por estereotipos fijados o por circunstancias vitales que, aun siendo de in-

\footnotetext{
${ }^{3}$ Lienzo, $116 \times 66 \mathrm{cms}$.

${ }^{4}$ Lienzo, $280 \times 220 \mathrm{cms}$.

${ }^{5}$ Figuró esta pintura en la Exposición Spanelske Umeni 17. a 18. Století. z Ceskoslovenskych Sbírek, Praha, Listopad, 1989 - Leden, 1990, n. ${ }^{\circ}$ 36. El catálogo fue redactado por Pavel Stepánek y en él esta pintura fue comentada y descrita a nombre de Roelas aunque no fue reproducida. Se recoge allí que la atribución se había realizado previa consulta a E. Valdivieso. Reproducimos ahora esta obra debido a que el propio Pavel Stepánek ha tenido la generosidad de facilitarnos la fotografía.
} 

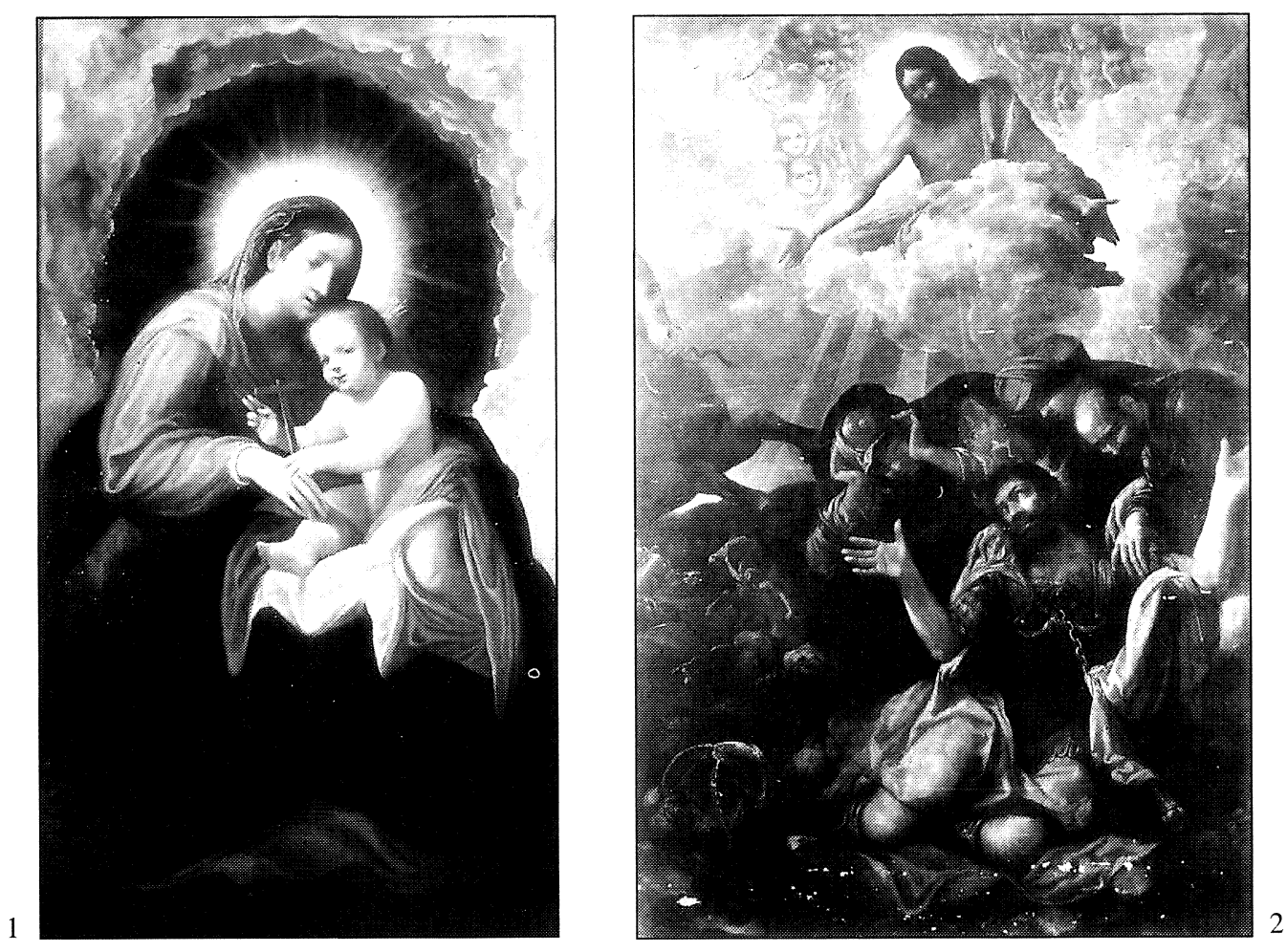

3

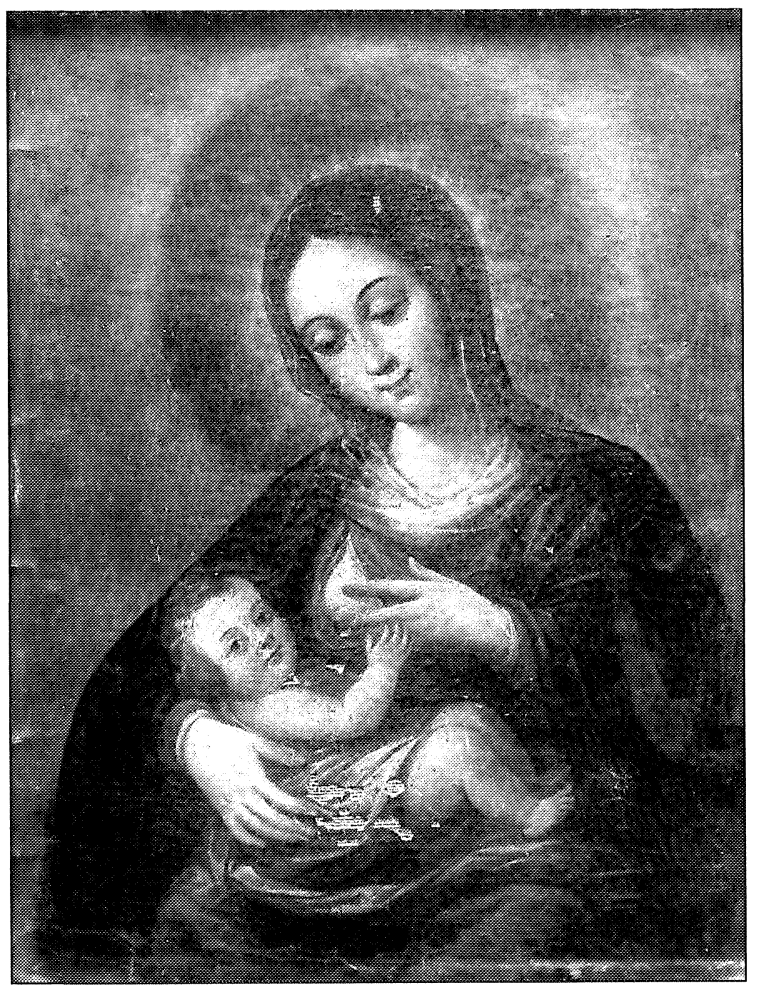

Fig. 1. J. de Roelas: Virgen con el Niño. Sevilla. Reales Alcázares.

Fig. 2. J. de Roelas: Conversión de San Pablo. Rep. Checa, Palacio de Mníchovo Hradiste. Fig. 3. J. del Castillo: Virgen con el Niño. Sevilla. Col. privada. 
terés, no explican por sí mismas su verdadera dimensión artística. Esto ocurre con la vida y la obra del pintor Juan del Castillo, tradicionalmente conocido como el maestro de Murillo y como el introductor en el ambiente local sevillano del siglo xvII de temas religiosos con personajes de modelo físico y actitud expresiva amable. Pero Castillo fue también un notable pintor, uno de los más jóvenes de su generación, vinculado en el tiempo con la pintura sevillana de la primera mitad del seiscientos. Castillo pudo nacer hacia 1590 y su trayectoria vital pudo extenderse hasta 1657, aunque no hay noticias directas suyas desde 1650, año en el que apadrinó a una nieta de Murillo. Los años que enmarcan su vida - muy similares a los que vivió el pintor más detacado de su generación en Sevilla, Francisco de Herrera el Viejo-, le permitieron conocer la evolución de la pintura barroca sevillana, desde el tardomanierismo y primer naturalismo, hasta el triunfo del naturalismo, e, incluso, la primera etapa o los albores del pleno barroco dinámico y escenográfico de la segunda mitad de dicho siglo, del que sería maestro indiscutible su discípulo Murillo. Pero Juan del Castillo no pertenece a ese mundo. Él, como los compañeros de su generación, se introduce en el barroco «bajo el signo del naturalismo» ${ }^{6}$. $\mathrm{Su}$ actividad se desarrolla en Sevilla en momentos de gran vitalidad en el ambiente pictórico local, donde convive con artistas como: Pacheco, Roelas, Herrera el Viejo, Zurbarán, el joven Velázquez, Alonso Cano y Murillo, entre otros. Sin embargo, su estilo, definido en plenitud en la década de los treinta del siglo xviI, demuestra una gran personalidad con dibujo a veces rígido y seco y gusto por los colores luminosos y también intensos llenos de matices, destacando su interés por los detalles naturalistas y su expresividad que, ya hemos indicado, fue generalmente amable y algo idealizada.

Intentando seguir un orden cronológico en cuanto a las obras que presentamos, algo difícil en la producción de Juan del Castillo, la primera sería una Virgen con el Niño (fig. n. ${ }^{\circ}$ 2), obra de pequeño formato, perteneciente a una colección particular sevillana ${ }^{7}$. Se trata de una pieza que reúne todas las características técnicas y de estilo propias de la producción de este pintor en su primera etapa, datada entre 1610 y $1620^{8}$. Asuntos como éste debieron sin duda salir de la mano de Castillo, así como en importante cantidad de su obrador, aunque de este formato, sencilla iconografía y etapa artística, no se conocía ninguno hasta el momento. La composición presenta el típico esquema triangular, en el que la imagen de la Virgen sentada, ante un fondo neutro, acentuado por los reflejos luminosos que rodean su cabeza, amamanta al Niño, que sostiene en su regazo y que vuelve su rostro hacia el observador de la obra, mientras la Madre inclina la cabeza con ternura a la derecha. Debe destacarse en esta pintura cierta sequedad en el dibujo, matizada por el gusto del pintor por los colores intensos, y la expresividad amable y complaciente de los personajes. Estas particularidades se verán acentuadas con la limpieza y restauración de la superficie pictórica de este cuadro, hoy día muy deteriorada. Es, pues, este pequeño lienzo una obra de devoción privada, que puede fecharse hacia 1615-1620, siendo provisionalmente la primera pieza con esta iconografía en la obra de Castillo y una de las primeras en la escuela sevillana, tras la apuntada anteriormente de Juan de Roelas. Este tipo de pintura recoge todos lo ingredientes devocionales propios de la religiosidad privada, sencilla y entrañable, que Castillo repetirá en varias ocasiones, aunque en diversos tamaños y actitudes en lo conservado y que más adelante Murillo desarrollará plena y magistralmente.

La pareja de Ángeles orantes o adorantes (figs. . $^{\circ} 3$ y n. ${ }^{\circ}$ ), que mostramos seguidamente, responde por su tipología a la de dos figuras sacadas de un cuadro de grandes dimensiones en el que se ha prescindido del tema central recortándolas ${ }^{9}$. Esta posibilidad se acrecienta por

\footnotetext{
6 Angulo, D., Pintura del siglo Xvil, en Ars Hispaniae, t. XV, Madrid, 1971, p. 76.

7 Lienzo, $28 \times 21 \mathrm{cms}$.

8 Valdivieso, E. y Serrera, J.M., Ob. cit., p. 305.

${ }^{9}$ Lienzos, $147 \times 80 \mathrm{cms}$.
} 

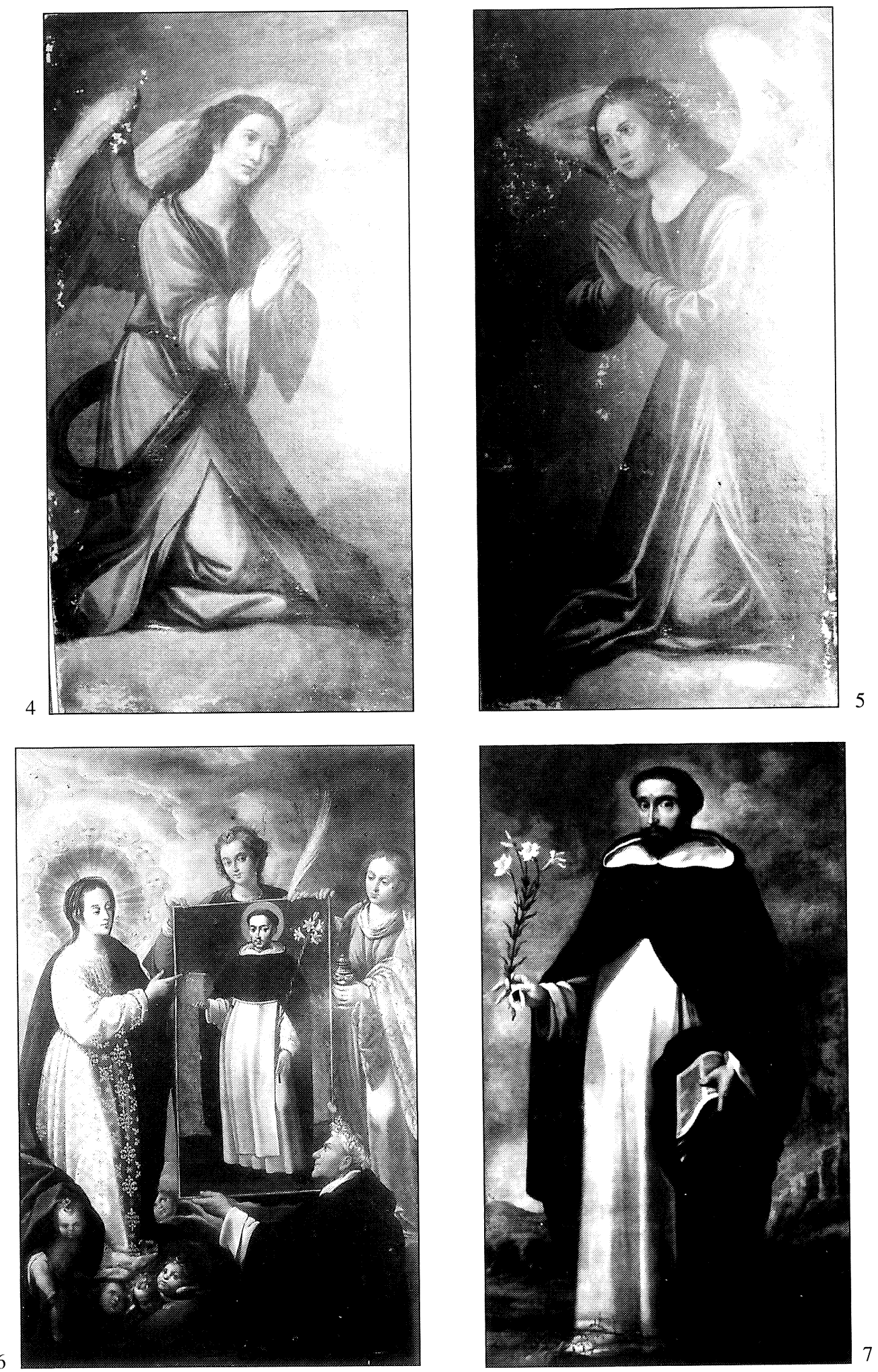

Figs. 4-5. J. del Castillo: Ángeles orantes. Sevilla. Col. privada.

Fig. 6. J. del Castillo: Santo Domingo en Soriano. Sala Christie's.

Fig. 7 J. del Castillo: Santo Domingo de Guzmán. París. Col. privada. 
los restos de pintura encontrados en las zonas de los lienzos unidos a los bastidores durante su reciente retauración que parecen confirmarlo. De no haber sido así, nada de extraño hubiera sido pensar, dadas su dimensiones, que estas piezas formaran en tiempos parte del remate de un retablo o de las puertas de un tríptico. Bien es cierto que en los retablos conocidos pintados por Juan del Castillo no se produce esta circunstancia iconográfica y que los trípticos no son presisamente frecuentes en el ambiente artístico sevillano. Ambos Ángeles son representados arrodillados sobre nubes, ante un fondo de celaje difuso, en actitud orante con las manos unidas a la altura del pecho. Sus rostros emanan una expresividad amable y elegante, lo que se acrecienta por la disposición mesurada de sus cuerpos y de las alas semidesplegadas. Este detalle hace pensar en una fuente iconográfica muy usual en las representaciónes angélicas en la escuela sevillana, especialmente en la de los ángeles mancebos. Se trata del grabado de Cornelis Cort, Anunciación con los profetas que predijeron la venida del Mesías, realizado sobre composición de Federico Zuccaro, ampliamente utilizado especialmente en la primera mitad del siglo xvir en Sevilla. Recoge el grabado un amplio repertorio físico y de actitudes en los ángeles que aparecen en el registro de gloria. Efectivamente Juan del Castillo parece inspirarse en los ángeles que en el grabado de Cort rodean la paloma del Espíritu Santo variando la disposición del rostro y la de los brazos. Se aprecia en estas obras un buen nivel creativo dentro de la producción de este pintor, caracterizada por su desigualdad. Las semejanzas físicas y de actitud de los personajes recuerdan y aproximan a estos ángeles con el Arcángel de la Anunciación, una de las hermosas pinturas que realizó Castillo para el retablo de la iglesia del colegio dominico de Santa María de Montesión, conservada en el Museo de Bellas Artes de Sevi1la. Por ello esta pareja de Ángeles orantes, debe fecharse hacia 1635.

La vinculación de Juan del Castillo con la Orden de Predicadores de Santo Domingo en la archidiócesis de Sevilla, quedó patente a lo largo de su trayectoria artística en la realización de diversas obras. Sin duda las más importantes fueron las citadas pinturas del retablo mayor de Montesión. Pero además pintó diversas versiones de temas tradicionalmente dominicos como: vírgenes del Rosario, retratos de Santo Domingo y otros santos de la orden y la Entrega del verdadero retrato de Santo Domingo al monje del monasterio de Soriano. Esta última iconografía, de carácter esencialmente mariano, refleja el amor filial de los miembros de la orden hacia la Virgen, cuestionado en Sevilla en la segunda década del siglo xviI tras la querella y sucesos inmaculadistas que allí se produjeron, y la protección que les brindaba la Madre de Dios. Por ello este asunto, conocido habitualmente como Santo Domingo en Soriano, apareció en la famosa serie encargada a Zurbarán para el convento de San Pablo, hoy parroquia de la Magdalena de Sevilla, hacia 1626, conservado en la capilla sacramental de dicha parroquia, o en uno de los retablos laterales del presbiterio de la iglesia del colegio de Montesión, cuya pintura central fue realizada por Juan del Castillo. Igualmente este pintor realizó la pintura del retablo frontero en la misma iglesia que representaba a Santo Tomás y San Vicente Ferrer.

Ese lienzo de Santo Domingo en Soriano de Montesión, fue citado en su primitiva ubicación por Ponz, Ceán Bermúdez y González de León. Considerado primero por Ponz del estilo del retablo mayor de Montesión, Ceán Bermúdez y González de León la atribuyen claramente a Juan del Castillo ${ }^{10}$. En 1810, la obra fue trasladada al Alcázar sevillano por las tropas francesas, catalogándose con sus medidas, en la sala a nombre de su autor, con el número $19^{11}$. A partir de entonces se ignoraba el recorrido seguido por esta pintura. Su similitud de medidas

${ }^{10}$ Ponz, A., Viaje de España, Madrid, 1772-1794, ed. 1974, t.IX, p. 786; Ceán Bermúdez, J.A., Diccionario Histórico de los más ilustres profesores de las Bellas Artes en España, Madrid, 1800, vol. I, p. 288; González de León, F., Noticia artística, histórica y curiosa... ciudad de Sevilla, Sevilla, 1844, ed. 1973, p. 973.

1 Gómez Imaz, M., Inventario de los Cuadros sustraídos por el Gobierno Intruso en Sevilla (Año 1810), Sevilla, 1896, ed. 1917 , p. 122. Lienzo, (2 1/2 x 2 varas) $209 \times 167 \mathrm{cms}$. 
con el cuadro del mismo asunto citado en el catálogo de la colección de Manuel Aguado, de 1839, con el número 19, y vendido en París, el 20 de marzo de 1843, describiéndose en el catálogo de venta y numerándose con el $105^{12}$, hizo a Valdivieso y Serrera, a la luz de estos datos, suponer con acierto que el cuadro procedente de Montesión era el allí catalogado ${ }^{13}$. Desde entonces carecíamos de noticias del mismo hasta que, en el mercado internacional de arte, apareció en 1990 un lienzo que representaba el asunto de Santo Domingo en Soriano (fig. n. ${ }^{\circ}$ 5), cuyas dimensiones coincidían con las ofrecidas por Gómez Imaz en el Inventario del Alcázar y su estilo correspondía perfectamente con el de madurez artística de Juan del Castillo, hacia $1635^{14}$.

Efectivamente la cronología de esta pintura, que con casi total seguridad fue la que figuró en el retablo colateral del presbiterio de Montesión, no parece sujeta a discusión, según nuestros conocimientos actuales. El análisis de estilo del lienzo y sus carácteristicas técnicas, lo sitúan en la fecha indicada, en un período similar al que habitualmente se asigna para la realización de las pinturas del retablo mayor de la iglesia de este colegio dominico, la mejores obras de Juan del Castillo. Sin embargo, el retablo que lo contenía fue realizado entre 1617 y 1618; pues concretamente el 13 de mayo de 1618, se concertó con Baltasar Quintero la policromía del mismo ${ }^{15}$. Pero los argumentos de estilo, en la evolución de la obra de Castillo, son tajantes, además se conserva una versión muy similar, aunque de menor calidad y de menor formato en el ancho, en el convento sevillano de Madre de Dios, fechada por Valdivieso y Serrera hacia 1635-1638 ${ }^{16}$. Este lienzo de Santo Domingo en Soriano, muestra un luminoso rompimiento de gloria, en el que la Virgen entrega el verdadero retrato de Santo Domingo al emocionado monje del convento de Soriano que lo recoge en la zona inferior izquierda de la obra. La acompañan Santa Catalina de Siena, que sostiene el retrato ayudada por Santa María Magdalena. A ambas santas se les reconoce con facilidad por sus atributos iconográficos.

La presencia de la figura de Santo Domingo en la obra de Juan del Castillo fue amplia y, además, recoge diversas icongrafías: efigies en diversos retablos, en pequeño y mediano formato, el Santo disciplinándose y, las ya citadas entregas del verdadero retrato en Soriano; los dos últimos asuntos en tamaños grandes o en lienzos de altar. No se conocían hasta el momento cuadros de un tamaño grande con la efigie de Santo Domingo, ataviado con el hábito de la orden y portando los símbolos tradicionales que le identifican iconológicamente. Recientemente hemos reconocido en una colección particular en París, un Santo Domingo de Guzmán (fig. n. ${ }^{\circ}$ ), obra de Juan de Castillo, no sólo destacable por sus dimensiones, sino por la gran calidad de ejecución ${ }^{17}$. El lienzo nos muestra la figura de tamaño natural de Santo Domingo, portando la bara de azucenas con los dedos pulgar e índice de la mano derecha y el libro, abierto, en la izquierda. La concepción del cuerpo y del hábito del personaje resultan monumentales, recortado ante un fondo de celaje superior y un tercio inferior de paisaje difuso de tonalidades grises azuladas y verdosas. Su expresividad, marcada en la mirada directa al observador de la obra, contrasta con otras interpretaciones de Juan del Castillo sobre esta imagen. Así en las

${ }_{12}$ Aguado, M., Catalogue des tableaux des Ecoles..., exposés dans la Galerie du Marquis de las Marismas, París, 1839, n. ${ }^{\circ}$ 19; Catalogue de Tableaux anciens des écoles espagnoles...composant la Gallerie de M. Aguado, Marqués de las Marismas, dont la vente aux encheres... le 20 mars 1843, París, 1843, n. $^{\circ} 105$.

13 Valdivieso, E. y Serrera, J.M., Ob. cit., 1985, pp. 355 y 356.

14 Christie's. Old Master Pictures. Londres, 19/XII/1990.

15 Muro Orejón, A., Pintores y doradores, en Documentos para la Historia del Arte en Andalucía, VIII, Sevilla, 1935 , pp. $79-85$.

${ }^{16}$ Lienzo, $210 \times 140 \mathrm{cms}$. Valdivieso, E. y Morales, A., Sevilla oculta, Sevilla, 1980, p. 105; Morales, E., Sanz, Mª., Serrera, J.M. y Valvivieso, E., Guía artística de Sevilla y su provincia, Sevilla, 1981, p. 88. Valdivieso, E. y Serrera, J.M., Catálogo de la Exposición: La época de Murillo..., Sevilla, 1982, n. ․ 29. Valdivieso, E. y Serrera, J.M., Ob. cit., 1985, p. 355; Valdivieso, E., Historia de la pintura sevillana, Sevilla, 1986, p.

17 Lienzo, $191 \times 107 \mathrm{cms}$. 
consideradas de primera época, la presencia del santo en pequeño formato resulta convencional en su estilo, mientras que en la tabla del retablo de la Encarnación de Santa María de Carmona, el idealismo corporal de tradición manierista está presente aún en la figura de Santo Domingo. Los retratos dominicanos presentes en los Santo Domingo en Soriano que se le atribuyen reponden todos a la misma tipología, consagrada por Zurbarán en la pintura para el convento de San Pablo, mostrando al Santo casi de frente, con la cabeza levemente girada o inclinada, aunque mirando al frente, con el libro cerrado en la mano izquierda y la vara de azucenas en la derecha, justo al revés de la obra que aquí presentamos.

En varias ocasiones se ha citado la influencia de Zurbarán sobre el trabajo de madurez de Juan del Castillo. Esa influencia habría que situarla en la órbita general del éxito y repercusión de la obra del gran pintor extremeño en la escuela sevillana. Desde 1630, aproximadamente, en la pintura de Juan del Castillo se advierte una tendencia a solemnizar los gestos y actitudes de los personajes y a simplificar las formas y los volúmenes. Pero esa depuración formal que impone el naturalismo es matizada por el estilo de Castillo que adquiere una personalidad propia y una expresividad singular. El paisaje de fondo que acompaña a este nuevo Santo Domingo de Guzmán, recuerda también al trabajo zurbaranesco a partir de 1638-1640, por lo que este detalle, junto con las características generales de la obra, nos permite datarla aproximadamente a partir de 1640 .

En el mercado español de arte, fue subastada en 1998 una Adoración de los pastores (fig. n. ${ }^{\circ}$ 7), vinculable con el estilo de Juan del Castillo, que anteriormente pertenecía a un propietario particular de Granada ${ }^{18}$. De este pintor se conocen y se conservan algunas Adoraciones de pastores, de las que sin duda la mejor fue la que formó parte del ya citado varias veces retablo dominico de Montesión, conservada actualmente en el Museo de Bellas Artes de Sevilla, punto de referencia habitual del trabajo de Castillo. Las versiones de la iglesia de San Juan Bautista de la Palma del Condado, Huelva, datada entre 1610-1615 ${ }^{19}$, posiblemente algo posterior, hacia 1625-1630, y la del convento de Santa Inés, en Sevilla, fechada hacia $1630^{20}$ y quizás algo anterior, hacia 1625; parecen pasos compositivos previos anteriores a la obra del Museo de Bellas Artes de Sevilla. La Adoración de los pastores que presentamos parece otro escalón previo más, y como las anteriores, aunque el de Santa Inés esté muy repintado, difícil de datar cronológicamente, ya que, además pudieran ser obras de taller. Sin embargo, la expresividad amable de los personajes, la técnica pictórica y los tonos cromáticos róseos y azules de la vestimenta de la Virgen, azules verdosos y sienas brillantes de otros personajes, nos permiten situar el lienzo a partir de 1630.

La composición de esta Adoración de los pastores nos muestra en primer plano a la Virgen arrodillada que, retirando los paños blancos que lo cubren, muestra al Niño tendido en el pesebre. Tras ella, a la derecha del lienzo, la figura de San José, con la bara patriarcal en la mano izquierda, cabeza inclinada en perspectiva hacia el asunto central del cuadro y marcada afectación anímica. No deja de ser curiosa la disposición de la Sagrada Familia que aparece a la derecha del lienzo, lo que no suele ser habitual en este tema en la pintura española y que Castillo no utilizó en sus otras obras del mismo asunto. Curiosamente su discípulo Murillo sí lo hizo, por ejemplo en la Adoración de los pastores del Museo del Prado, fechable hacia 1660, por lo que es posible que Castillo ya conociera el grabado de Boetius a Bolstwert, sobre composición de Abraham Bloemaert, inspirándose en los personajes del grupo central invertidos, en el que se incluirían los dos pastores arrodillados que rodean al Niño. Tras estos últimos, a la izquierda del lienzo, aparecen el resto de pastores y personajes humildes que acuden a ado-

\footnotetext{
18 Lienzo, $170 \times 135 \mathrm{cms}$. Subastas Castellana, 29 de septiembre de 1998, n. ${ }^{\circ} 199$.

19 Valdivieso,, E. y Serrera, J.M., Ob. cit., p. 304, n. ${ }^{\circ}$ 101, lám. 248.

20 Id., p. 345. n. ${ }^{\circ} 102$, lám. 249.
} 

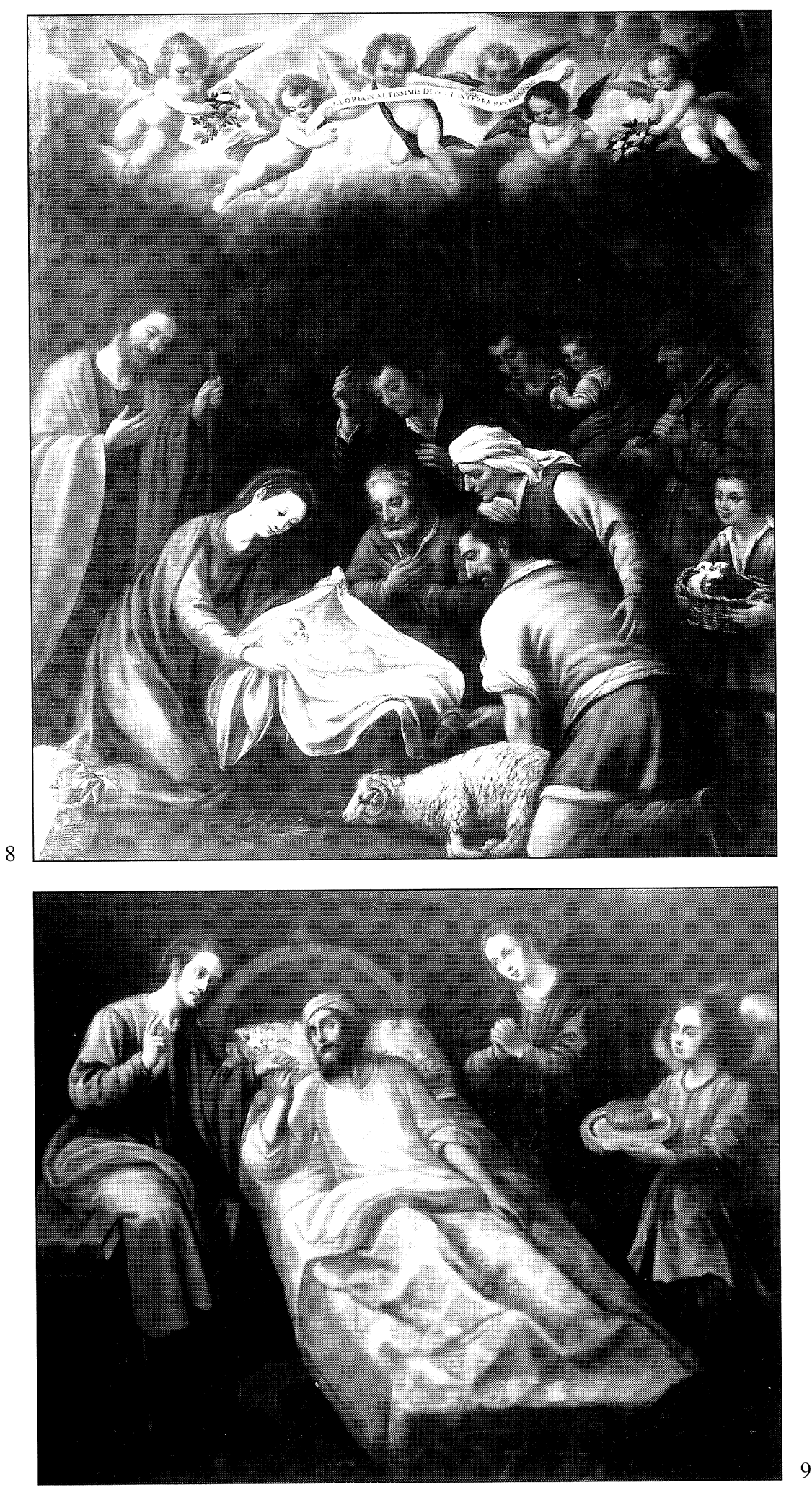

Fig. 8. J. del Castillo: Adoración de los pastores. Granada. Col. privada. Fig. 9. J. del Castillo: La muerte de San José. Sevilla. Col. privada. 
rar y portan ofrendas. Curioso es señalar la presencia del personaje infantil que lleva en un cesto dos pichones, siempre presente en todos las versiones que Castillo hace de este asunto disponiéndole en distintos lugares; en este caso se sitúa en la zona inferior izquierda. El naturalismo que preside la obra se resalta en primer plano por la presencia del cordero atado y una cesta de mimbre con telas del ángulo inferior derecho. Juan del Castillo demuestra en esta pintura conocer el tenebrismo, aunque lo practique de manera poco diestra, como demuestra la iluminación artificiosa pero nada precisa de la composición. Este pintor se mueve con mayor agilidad en atmósferas luminosas, como se advierte en sus mejores trabajos. De gran interés resulta el rompimiento de gloria con la presencia, entre nubes doradas, de seis ángeles niños que portan flores y una filacteria que dice: «GLORIA IN ALTISSIMIS DEO ET IN TERRA PAX HOMÍNIBUS». Las figurillas angélicas, en escorzos discretos, tienen un encanto formal y expresivo que presagia nuevamente el estilo de Murillo.

La Muerte de San José es un tema apócrifo, de indudable valor piadoso, del que Juan del Castillo dejó una tabla en el banco del retablo principal de Montesión, conservada hoy día en el Museo de Bellas Artes de Sevilla. Se trata de una pintura, rematada en medio punto, cuyo formato alargado condiciona la composición ${ }^{21}$. Recientemente hemos localizado, en una colección particular sevillana, otra Muerte o Tránsito de San José (fig. n. ${ }^{\circ}$ 9), plenamente atribuible en estilo y técnica a la obra de Juan del Castillo y que supera la calidad de la tabla del retablo dominico ${ }^{22}$.

El lienzo presenta una composición apaisada, aunque condicionada por la disposición rampante del lecho de San José, que marca una diagonal de derecha a izquierda y separa el resto de personajes que intervienen en la misma. De izquierda a derecha, sobre fondo de penumbra, aparece un ángel que porta un plato de metal con un recipiente gallonado. Tras él, al lado de la cama, la Virgen en actitud orante. En el centro, la figura del patriarca San José, que resulta sumamente rígida y de difícil disposición en tan violenta perspectiva, vuelve su rostro enfermo y cansado hacia Cristo quien coge la mano izquierda que éste le ofrece en su agonía. La cama muestra cabecero de madera con remates de diseño manierista, almohada y colcha bordada. A la derecha, Cristo sentado sobre un banco, le bendice. Es curiosa la presencia en un plano preeminente de un volumen, en cuyo lomo se lee «Biblia Sacr», colocado sobre el mismo asiento en que aparece Cristo.

La presencia destacada de este ejemplar de la Sagrada Biblia, resulta ciertamente curiosa en este asunto ya que José es un personaje poco citado en los Evangelios canónicos. La mayoría de las escenas de su vida son narradas por los Evangelios Apócrifos, en el Protoevangelio de Santiago y la Historia de José el carpintero. La leyenda indica que San José murió anciano, a los ciento once años, pero de los Evangelios se deduce que debió morir antes de la Pasión de Cristo. Aun así la leyenda prevalece en la iconografía cristiana sobre este asunto, y el patriarca, venerable anciano, es asistido en su agonía por Cristo y la Virgen, acompañados en algunas ocasiones de los arcángeles Miguel y Gabriel que toman su alma. En muchas ocasiones, sobre esta escena aparece un rompimiento de gloria, que anuncia su subida al cielo en alma y cuerpo, pues San José recibió el privilegio de mantener su cuerpo incorrupto hasta el Juicio Final. Este último detalle no está presente en este Tránsito de San José, aunque sí en la tabla de Montesión del Museo sevillano. Por lo demás, aunque en general se repitan las expresiones, esta obra supera en elegancia formal y emotividad a la del banco del conocido retablo dominico. En ella están presentes todas las desigualdades y rigideces de dibujo que caracterizan la labor de Juan del Castillo, así como sus dificultades a la hora de trazar composiciones de

\footnotetext{
${ }^{21}$ Id., p. 340 , n. $^{\circ} 86$, lám. 233. Mide 100 x $56 \mathrm{cms}$.
}

22 Lienzo, $152 \times 125 \mathrm{cms}$. 

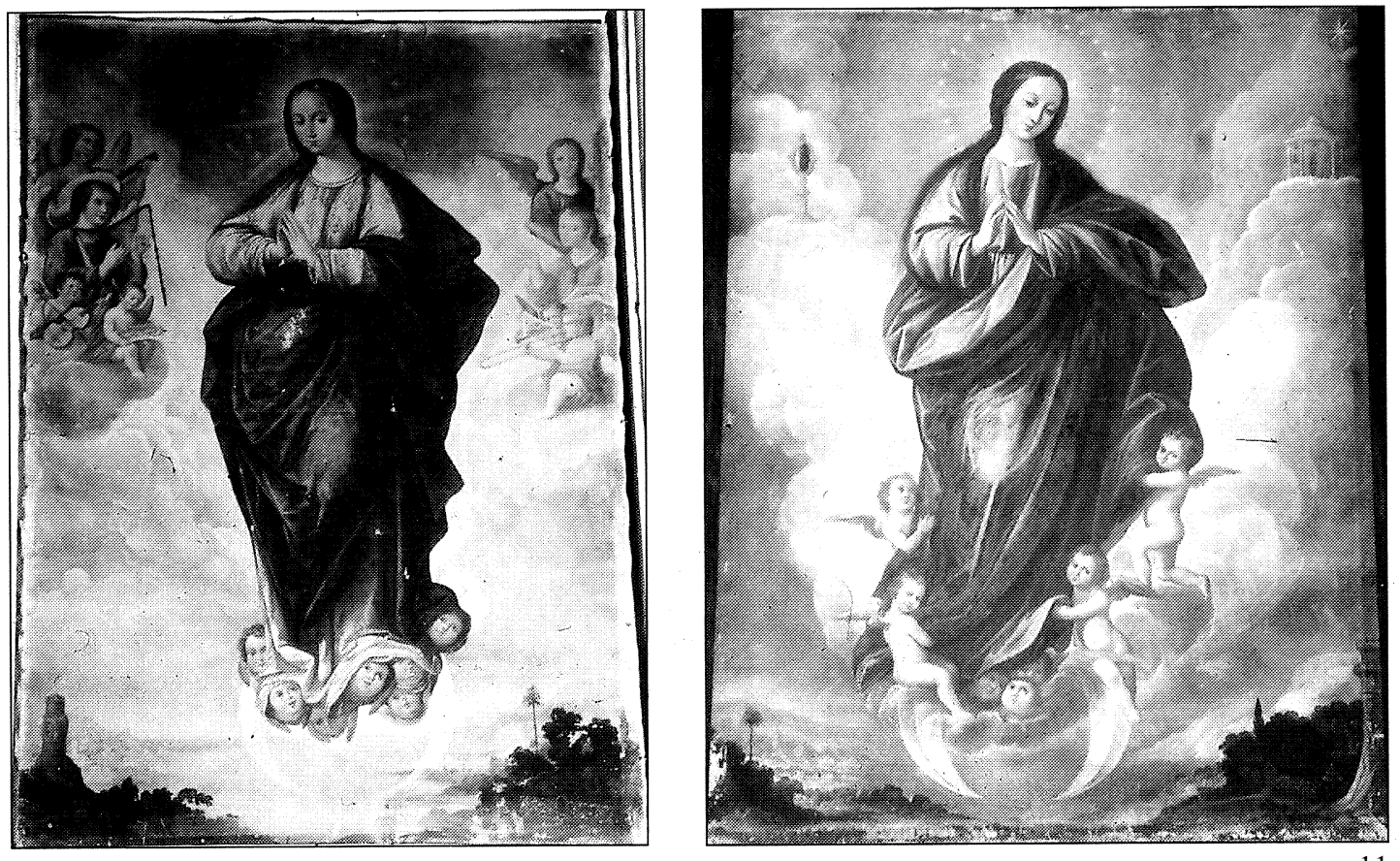

10

12
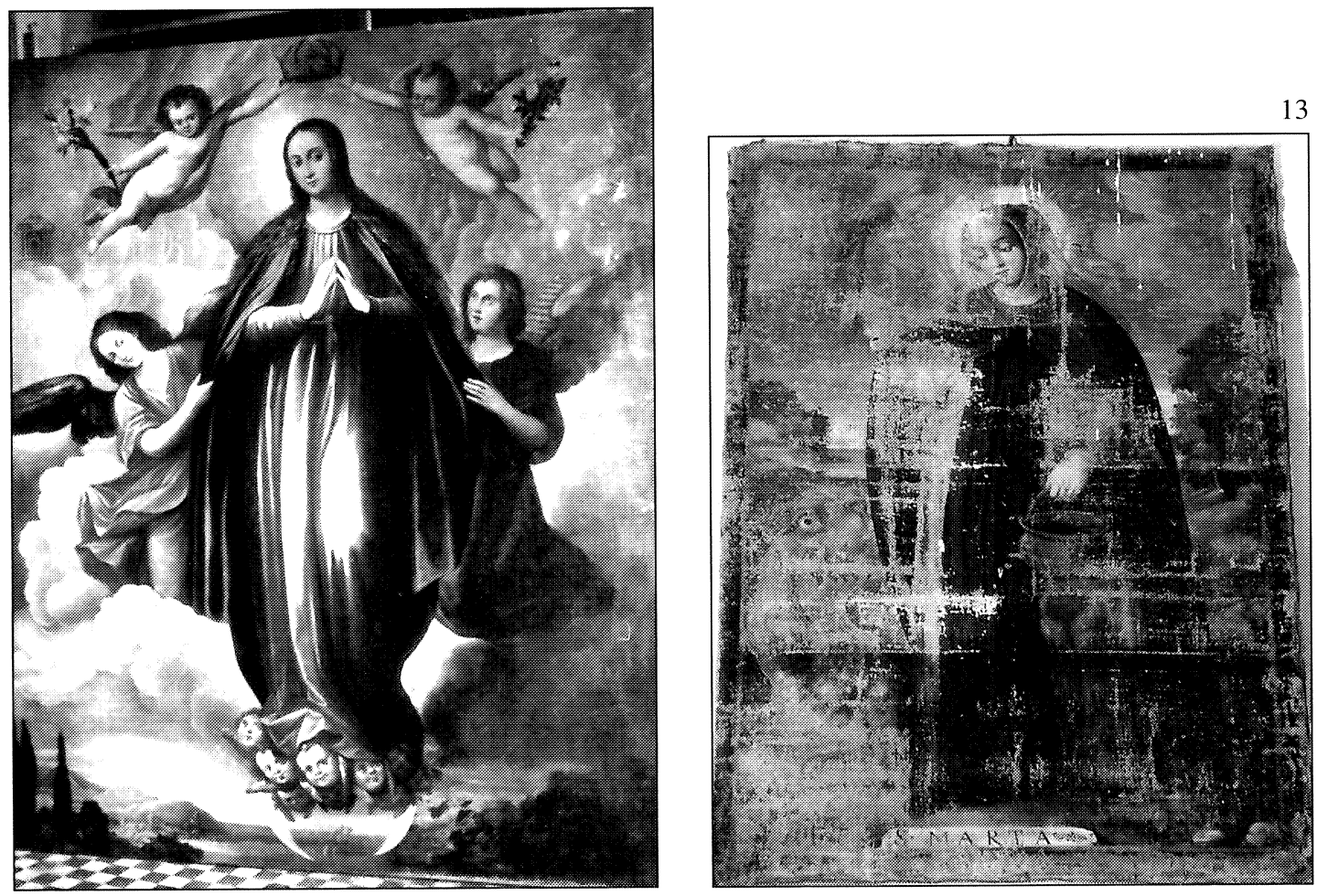

Figs. 10-12. J. del Castillo: Inmaculada Concepción. Carmona (Sevilla). Convento de la Trinidad (10 y 11) y Sevilla, Col. privada.

Fig. 13. J. del Castillo: Santa Marta. Carmona (Sevilla). Convento de la Trinidad. 
perspectiva algo compleja. Pero también pueden observarse las cualidades de su trabajo en el sentido de lo cromático y en su naturalismo amable. Estas apreciaciones permiten fechar la obra con anterioridad a 1635.

A los pies de la nave del evangelio de la iglesia del convento de la Trinidad de Carmona, Sevilla, actualmente ocupado por religiosas agustinas recoletas, se encuentra en el muro, sobre un pequeño retablo dedicado a la Virgen de Guadalupe, un lienzo que representa la Inmaculada Concepción (fig. n. ${ }^{\circ} 10$ ), enmarcado en una orla decorativa de falsa piedra que debe proceder de las remodelaciones que desde el siglo xviII ha sufrido este templo ${ }^{23}$. Se trata de una obra de calidad destacable que la bibliografía artística había reseñado muy de pasada, advirtiendo sobre su posible cronología pero sin precisar atribución artística de ningún tipo ${ }^{24}$. Recientemente, durante unas labores de inventario realizadas en Carmona, hemos podido estudiar detenidamente este lienzo y vincularlo plenamente con la producción de Juan del Castillo, en etapa difícil siempre de precisar, pero que creemos debe rondar el año 1630, esencialmente por sus características iconográficas. Se trata de una pintura en la que el pintor ha seguido los dictámenes iconográficos trazados por Francisco Pacheco en el Arte de la pintura... ${ }^{25}$, es decir, la Inmaculada Concepción, según la visión de la beata portuguesa Beatriz de Silva, ataviada con túnica blanca y manto azul, posada sobre la luna en disposición creciente y una peana de cabezas de querubes y la cabeza orlada de doce estrellas y resplandores que parten de la frente. La disposición física de la figura presenta un ritmo ondulante por la flexión de la pierna izquierda y el movimiento de las manos orantes hacia la derecha, siempre del lienzo, y volumetría marcada de los paños. El fondo de celaje, amplio y luminoso, presenta a ambos lados un coro de ángeles niños y mancebos que portan instrumentos musicales. En la zona inferior, un profundo paisaje, con los símbolos de las Letanias, recuerda a los empleados por Pacheco en sus Inmaculadas de la segunda década del siglo xvir y no es ajeno a los trazados por Zurbarán.

En el coro bajo de la clausura del mismo convento de la Trinidad de Carmona, se conserva otra Inmaculada Concepción (fig. n. ${ }^{\circ} 11$ ), también vinculable con la producción de Juan del Castillo, aunque se trate de una pieza de menor entidad artística que la anterior y por lo tanto haya que advertir la intervención en ella del taller ${ }^{26}$. La icongrafía mariana presenta algunas diferencias con respecto a la anterior pintura. La vestimenta de la Virgen es de túnica jacinto róseo y manto azul verdoso que envuelve la mayor parte del cuerpo y da volumen y majestuosidad a la figura. La imagen presenta actitud orante con las manos unidas ante el pecho y la cabeza ligeramente inclinada hacia la derecha. De esta, de la frente, parte un halo rematado por estrellas. Rodean la figura los símbolos de las Letanias dispuestos entre las nubes que la envuelven y en el reducido paisaje de la parte inferior del lienzo. El pintor, en su trabajo ha seguido en buena medida los criterios iconográficos planteados en la escuela sevillana del primer tercio del siglo xviI, especialmente respeta los criterios teóricos de Pacheco a la hora de mostrar la disposición de la zona iluminada de la luna a los pies de la Virgen. En este caso a las cabezas de querubes tradicionales a los pies de la Inmaculada hay que unir cuatro ángeles niños que la elevan ${ }^{27}$. Puede fecharse esta pieza hacia $1625-1630$. Se conserva en una colec-

\footnotetext{
${ }^{23}$ Lienzo, $170 \times 110 \mathrm{cms}$. La superficie pictórica presenta algunas roturas y despredimientos.

${ }^{24}$ Hernández Díaz, J., Sancho Corbacho, A. y Collantes de Terán, F., Catálogo artístico de Sevilla y su provincia, t.I, Sevilla, 1955, p. 190; Morales, A. et alt., Guía artística de Sevilla y su provincia, Sevilla, 1981, p. 384; Id., Inventario artístico de Sevilla y su provincia, Madrid, 1982, p. 69; Calvo Laula, A., Carmona. Ciudad y monumentos, Carmona, 1993, p. 90.

251649 , ed. 1990 (Bassegoda, B.), pp. 575 - 577.

${ }^{26}$ Lienzo, $150 \times 110 \mathrm{cms}$. La pintura presenta algunos deterioros y deprendimientos en la parte inferior del lienzo.

${ }^{27}$ Citada sin atribución alguna en: Hernández Díaz, J., Sancho Corbacho, A. y Collantes de Terán, F., Catálogo artístico de Sevilla y su provincia, t.I, Sevilla, 1955, p. 190; Morales, A., Sanz, M ${ }^{\mathrm{a}}$.J., Serrera, J.M. y Valdivieso, E., Inventario artístico de Sevilla y su provincia, Madrid, 1982, p. 71.
} 
ción particular de la misma localidad de Carmona, en la parroquia de Santa María, una Inmaculada Concepción de características artísticas muy similares a ésta, fechada hacia $1625^{28}$.

$\mathrm{Al}$ estilo y a los modelos físicos habituales en la pintura de Juan del Castillo pertenece también esta otra Inmaculada Concepción ${ }^{29}$, de una colección privada de Sevilla (fig. n..$^{\circ} 12$ ). En ella el pintor ha seguido criterios iconográficos diferentes a las anteriores, inspirándose en un trabajo de Giuseppe Cesari, el Caballero de Arpino. De este pintor italiano, uno de los artistas que había contribuido a fijar los cánones contrarreformistas de esta iconografía, se conservaban actualmente en Sevilla varias versiones de taller o copias de sus Inmaculadas (Academia de Bellas Artes de Sevilla o Museo de Bellas Artes). Ambas tienen como referente el original la Inmaculada Concepción, de la Academia de San Fernando, en Madrid, procedente también de Sevilla, llevada allí en tiempos de la Guerra de la Independencia ${ }^{30}$. Juan del Castillo ha seguido fielmente el modelo de la Academia madrileña variando algunos elementos menores y la disposición del paisaje inferior. Así cambia la forma de la corona con imperiales que sostienen los ángeles superiores, portando éstos lirios y rosas. Los cúmulos de nubes son de mayor intensidad, y en ellos aparecen varios de los símbolos de las Letanías. Más característico de la escuela sevillana resulta el paisaje inferior, cercano a los utilizados por Pacheco, al igual que la disposición de la zona iluminada de la luna. Puede datarse este lienzo hacia 1620-1625, en una etapa previa a la producción de mayor calidad de Castillo.

En el coro alto de la clausura del convento de la Trinidad de Carmona, Sevilla, se encuentra también un curioso lienzo que había pasado inadvertido para la crítica artística hasta el momento. Ciertamente su estado de conservación es deplorable, pues está totalmente destensado del bastidor y la superficie pictórica, totalmente reseca, presenta grandes lagunas. A pesar de ello hemos podido estudiar esta obra con profundidad y conocer que se trata de una representación de Santa Marta (fig. n. ${ }^{\circ}$ 13), trabajo plenamente vinculable con el estilo de Juan del Castillo, y datable hacia 1620-1625 ${ }^{31}$. La Santa ha sido representada, según la iconografía que la muestra, como un San Jorge femenino domando al dragón, tarasca al que asperjea con un hisopo que porta en la mano derecha mientras que en la izquierda lleva el acetre. El personaje, con hábito religioso marrón, velada y con halo en la cabeza, aparece ante un amplio paisaje, con el dragón fluvial a su derecha. A los pies una inscripción reza: «S. Marta».

\footnotetext{
${ }^{28}$ Valdivieso, E. y Serrera, J.M., Ob. cit., p. 342, n. ${ }^{\circ} 98$, lám 246.

${ }^{29}$ Lienzo, $200 \times 140 \mathrm{cms}$.

30 Pérez Sánchez, A., Inventario de las Pinturas de la Academia de San Fernando, Madrid, 1964, n. ${ }^{\circ}$ 16; Pintura italiana del siglo XVII en España, Madrid, 1965, p. 220, lam. 55.

${ }^{31}$ Situado sobre la reja del coro alto de este convento, el lienzo es inaccesible para su medición.
} 